\title{
Investigating the Relationship between Organizational Justice, Organizational Trust, and Financial Corruption: Case Study in Valiasr Hospital of Tuyserkan City
}

\section{Zahra Zobdeh (BSc) ${ }^{1}$, Mokhtar Soheylizad (MSc)², Elahe Ezati (MSc) ${ }^{2}$, Vahid Shafieipour (MSc) $^{3, *}$, Davood Raziee (AD) ${ }^{4}$}

${ }^{1}$ BSc in Nursing, Valiasr Hospital of Tuyserkan city, Hamadan University of Medical Sciences, Hamadan, Iran

${ }^{2}$ PhD Candidate of Health Education and Promotion, School of Public Health, Hamadan University of Medical Sciences, Hamadan, Iran

${ }^{3}$ MSc in Business Management, Department of management, Tuyserkan Branch, Islamic Azad University, Tuyserkan, Iran

${ }^{4} \mathrm{AD}$ in Operating Room, Valiasr Hospital of Tuyserkan city, Hamadan University of Medical Sciences, Hamadan, Iran

* Corresponding Author: Vahid Shafieipour, Department of management, Tuyserkan Branch, Islamic Azad University, Toyserkan, Iran.Email: shafieipour58@yahoo.com

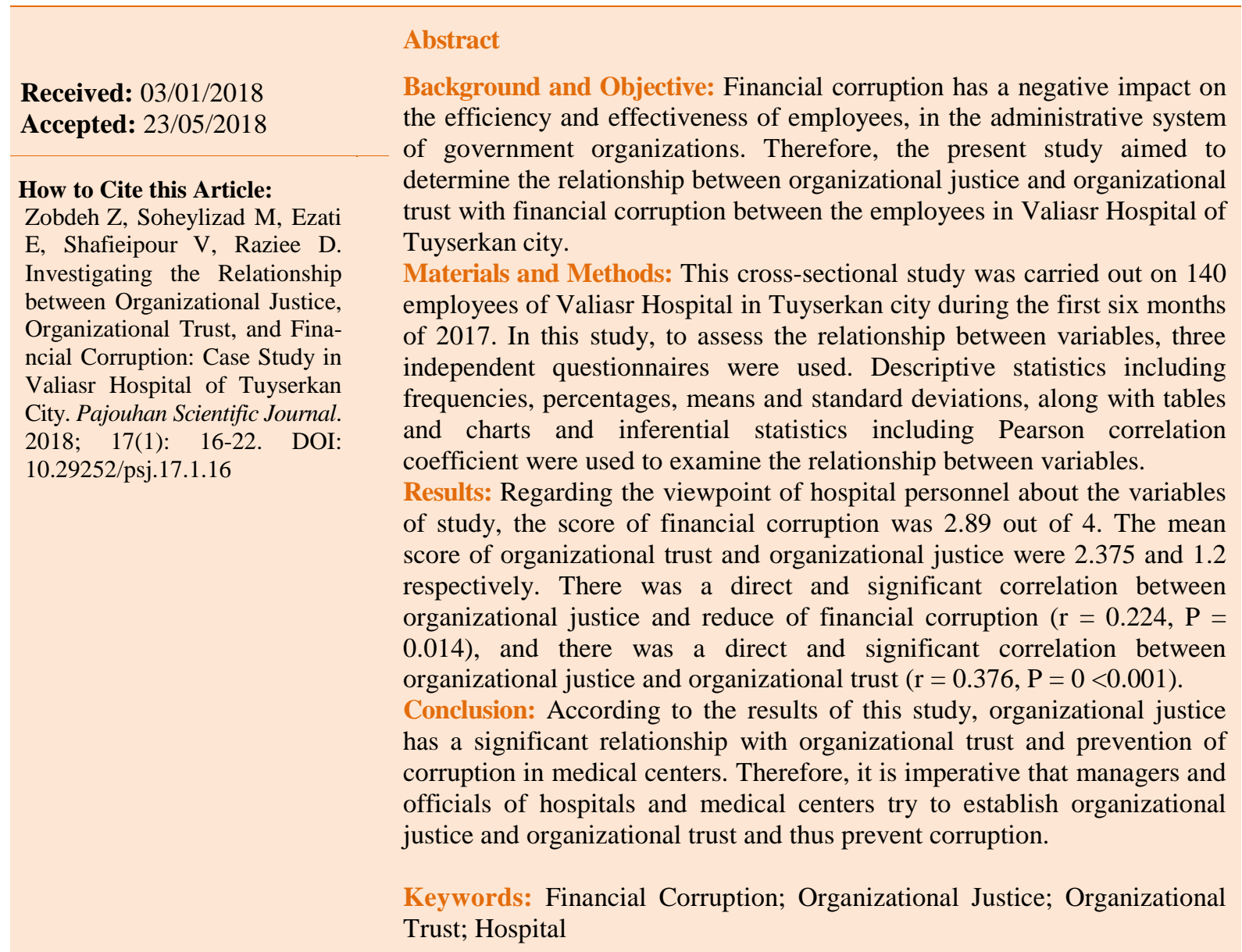


dof: $10.29252 /$ psj.17.1.16

بررسى رابطه عدالت سازمانى، اعتماد سازمانى و فساد مالى: مطالعه موردى بيمارستان وليعصر تويسر كان

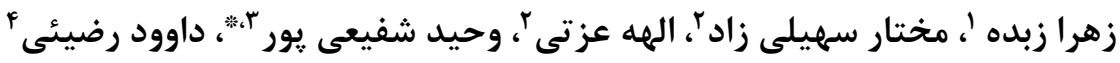

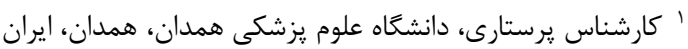

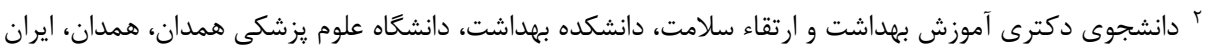

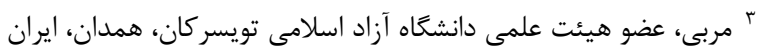

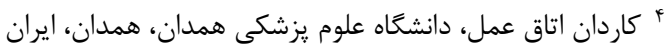

* نويسنده مسئول: وحيد شفيعى يور، مربى، عضو هيئت علمى دانشكاه آزاد اسلامى تويسر كان، همدان، ايران. ايميل: shafieipour58@yahoo.com

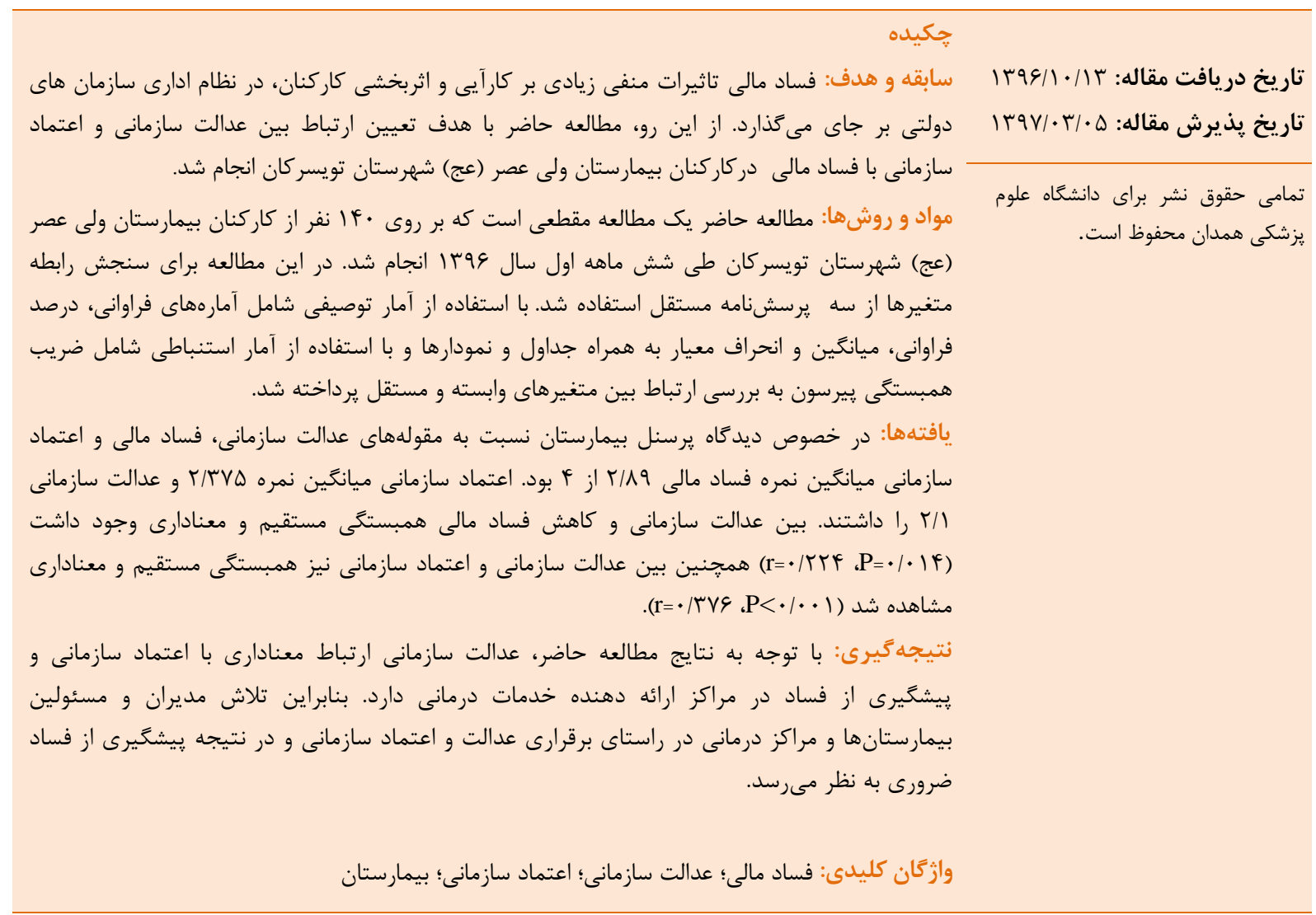

مقامه

انحصارطلبى و مشاركت عموم مردم در تعيين سرنوشت مىشود

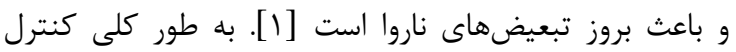

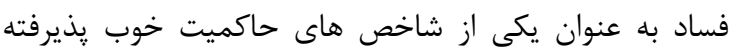

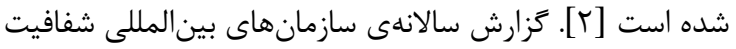

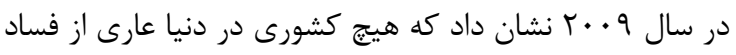

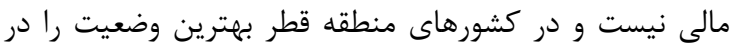

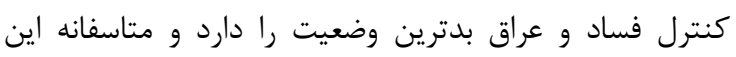

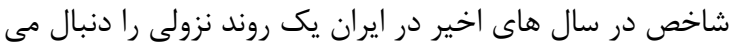

فساد مالى، نقش و تاثيرات منفى زيادى بركارآيى و

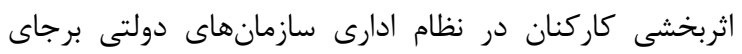

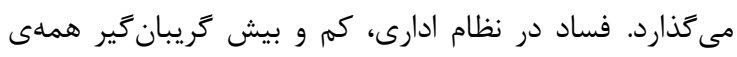

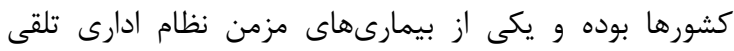

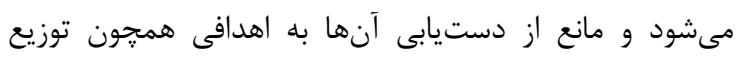

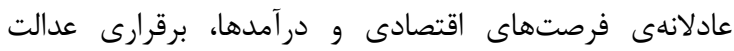
اجتماعى و افزايش رفاه عمومى، احقاق حقوق اشخاص ذى حقى حق،

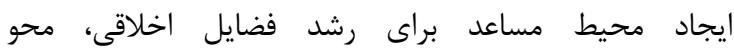




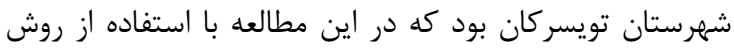

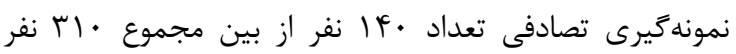

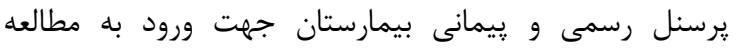

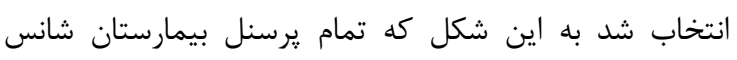

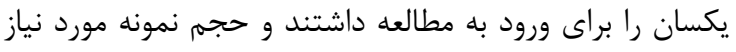

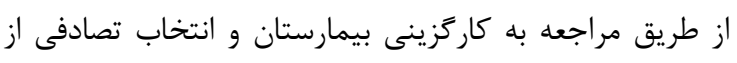

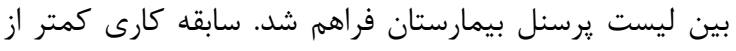

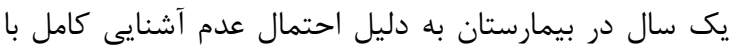

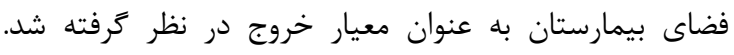

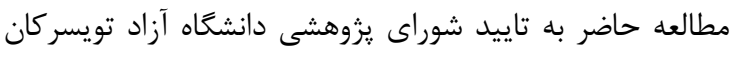

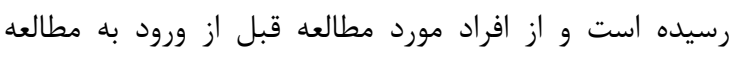
رضايت آكاهانه اخذ شد. به منظور دستيابى به اهداف تحقيق سه ير برسشنامه

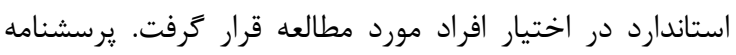

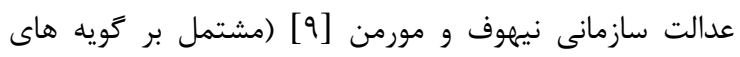

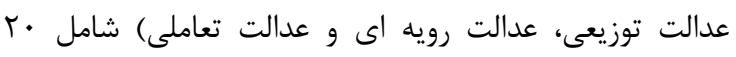

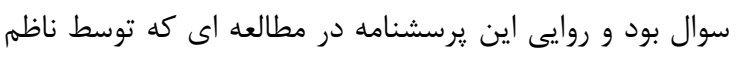

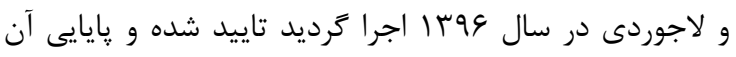

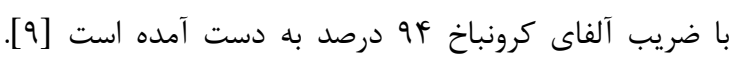

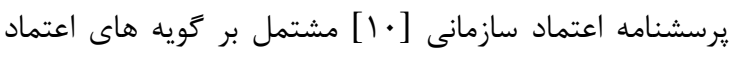

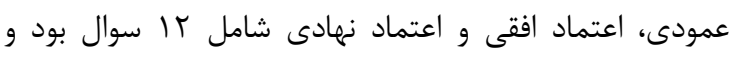

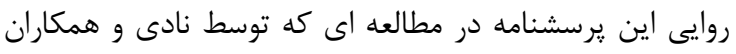

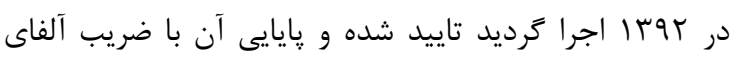

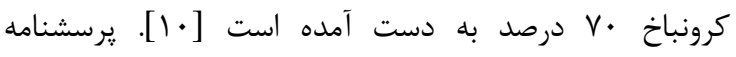

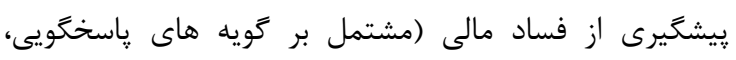

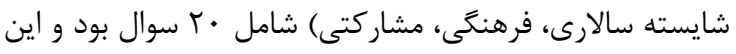

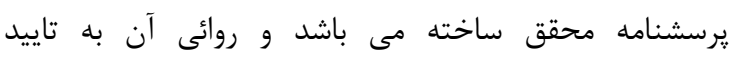
متخصصان مربوطه رسيد و وِايايى آن نيز با با استفاده از آلفاى

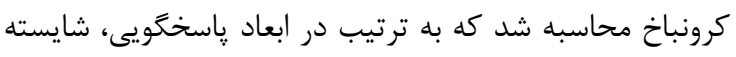

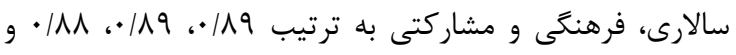

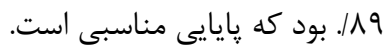

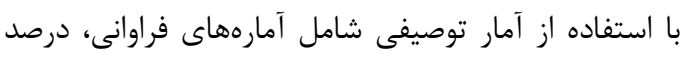

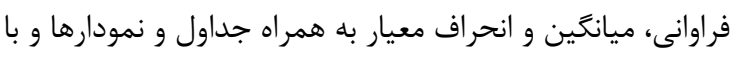

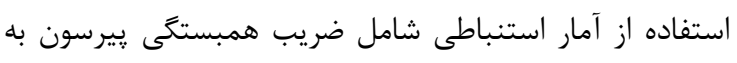

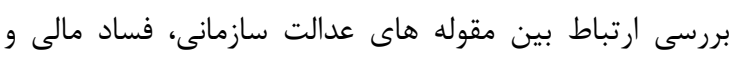

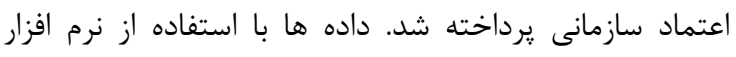

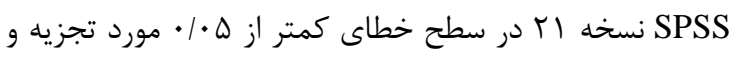

$$
\text { تحليل قرار گرفتند. }
$$

يافته ها

از مجموع • أl نفر از يرسنل بيمارستان كه به سوالات

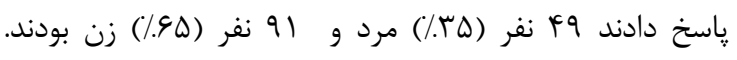

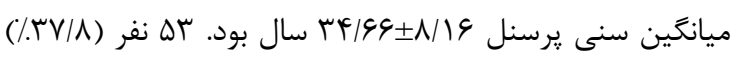

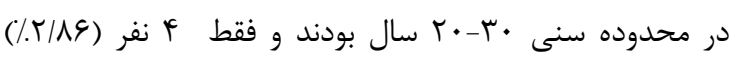

كند [1] اعتماد، تاثيرات مهم و مثبتى بر نتايج سازمانى دارد.

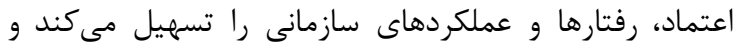

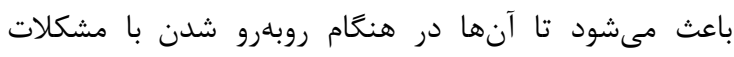

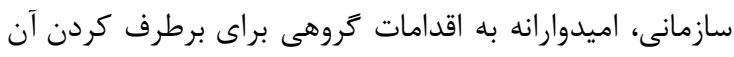

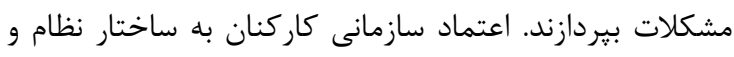

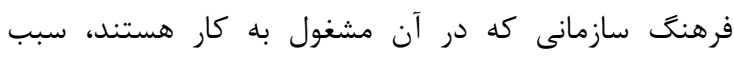

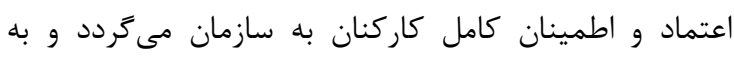

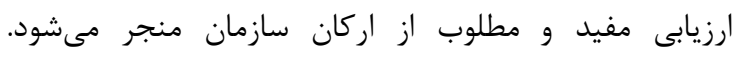

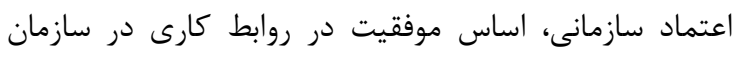

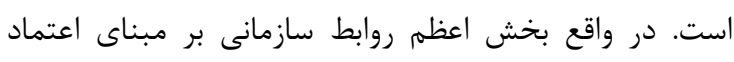

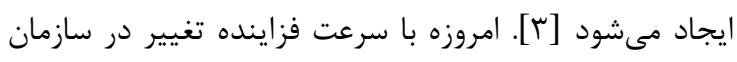

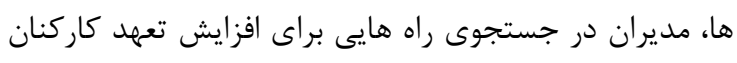

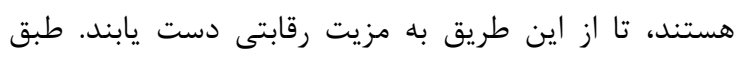

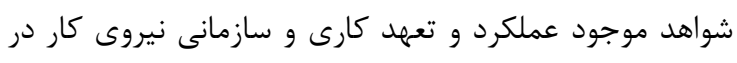

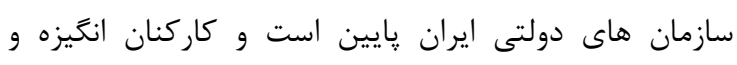

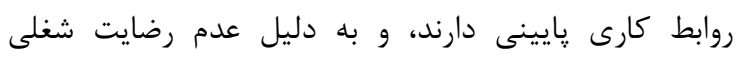

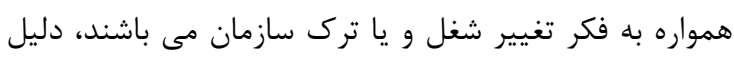

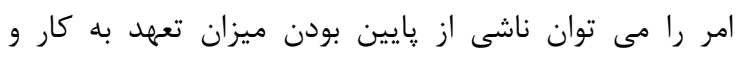

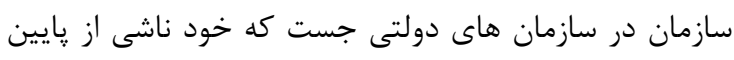

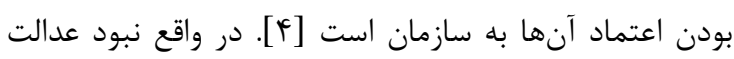

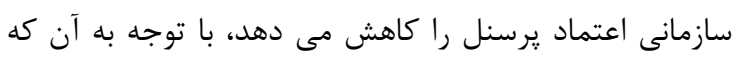

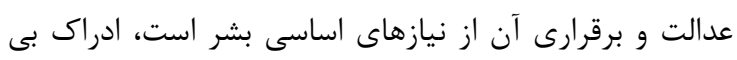

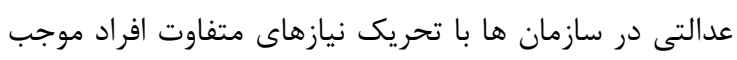

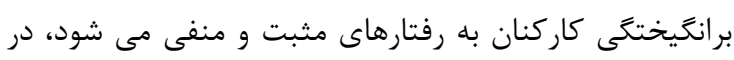

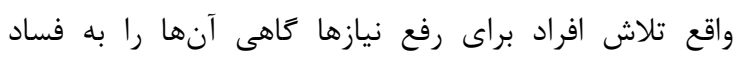
متمايل مى كند [ه]].

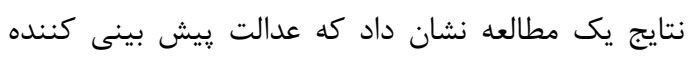

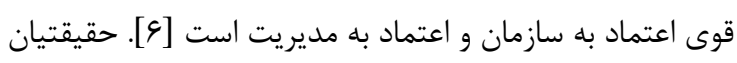

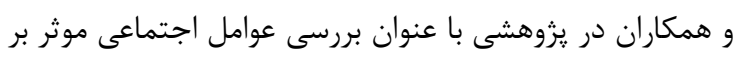

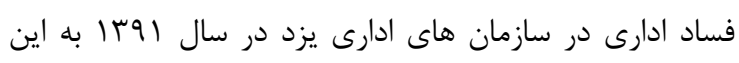

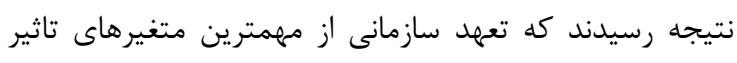

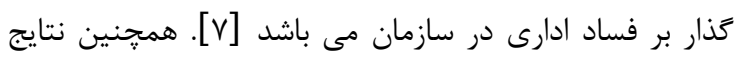

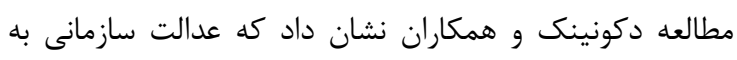

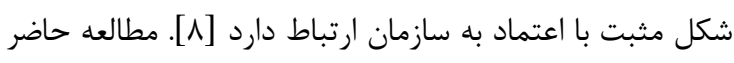

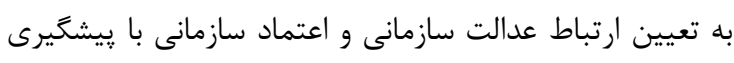

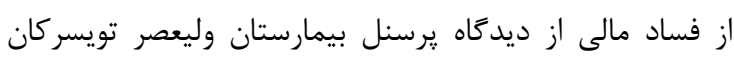
يرداخته است.

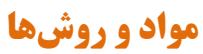

مطالعه حاضر يك مطالعه مقطعى (توصيفى - تحليلى) بود

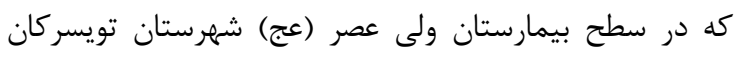

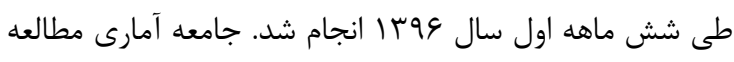

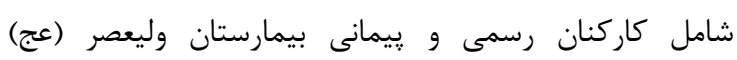


در جدول r ديدگًاه يرسنل بيمارستان نسبت به مقوله هاى

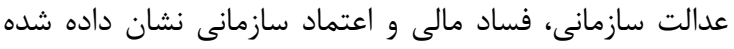

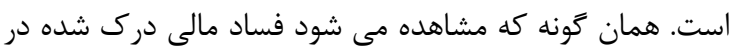
بين يرسنل با نمره T/VY

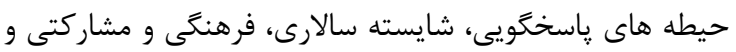

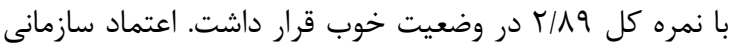

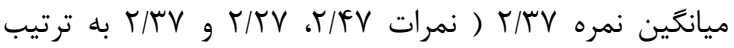

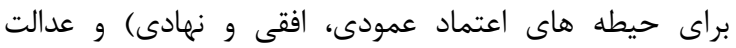

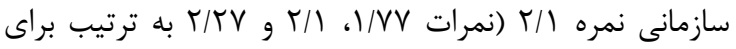

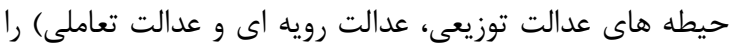
داشتند و در محدوده ضعيف بودند. در حيطه هاى عدالت

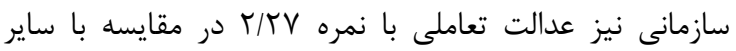
حيطه ها، ميانگين نمره بيشترى را كسب كرده بود و عدالت توزيعى درك شده بين يرسنل ضعيف بود. ضريب همبستگى بين مقوله هاى عدالت سازمانى، فساد

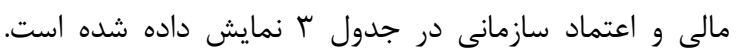

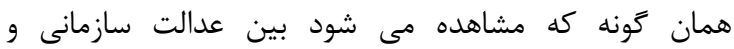
ي يشخيرى از فساد مالى همبستخى مستقيم و معنادارى مشاهده

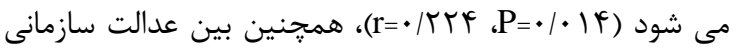

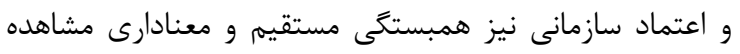

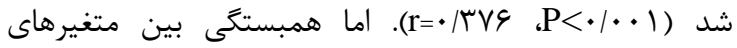

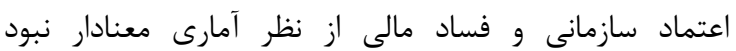
$(\mathrm{r}=\cdot / 1) \cdot \mathrm{P}=\cdot / \mathrm{TV})$

ضريب همبستگى بين حيطه هاى مربوط به عدالت سازمانى

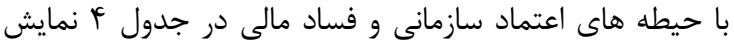

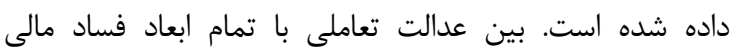

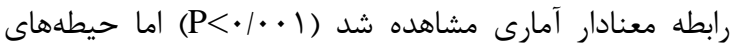

بالاى •ه سال سن داشتند. از نظر تحصيلات نيز هه. يرسنل مورد مطالعه مدرك كارشناسى داشتند و فقط أ نفر تحصيلات

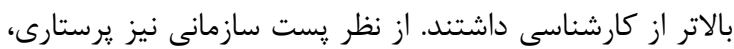

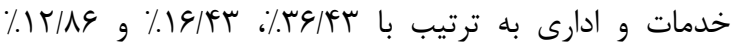

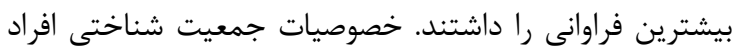
مورد مطالعه در جدول ا نشان داده شده است. رئ.

جدول (: خصوصيات جمعيت شناختى يرسنل مورد مطالعه

\begin{tabular}{|c|c|c|c|}
\hline درصد & تعداد & & متغير \\
\hline ra & $4 q$ & مرد & \multirow{2}{*}{ جنسيت } \\
\hline $9 \Delta$ & 91 & زن - ت ان & \\
\hline rV/AS & $\Delta r$ & $r \cdot-r \cdot$ & \multirow{4}{*}{ كروه سنى } \\
\hline rI/Fr & fF & rI-r. & \\
\hline TVIAS & ५q & $\langle i|-\phi$. & \\
\hline r/A & F & $\Delta 1-9$. & \\
\hline $11 / 4 \pi$ & 19 & زير دييلم & \multirow{5}{*}{ تحصيلات } \\
\hline $1 N / \Delta V$ & re & ديِلم & \\
\hline $\mid r / I F$ & IV & كاردان & \\
\hline$\Delta \Delta$ & VV & كارشناس & \\
\hline r/A & f & ارشد و بالاتر & \\
\hline $19 / 4$ & r & خدمتگزار & \multirow{7}{*}{ سازمانى } \\
\hline re/4 & DI & يرتار & \\
\hline $\mid r / \Lambda 9$ & 11 & ادارى & \\
\hline $14 / 7 q$ & $r \cdot$ & رشته هاى ييرايزشكى" & \\
\hline $1 \cdot / \mathrm{VI}$ & 10 & بهيار & \\
\hline$\cdot / V 1$ & 1 & يزشك & \\
\hline$N / \Delta V$ & ir & ماما & \\
\hline
\end{tabular}

*شامل رشته هاى اتاق عمل، بيهوشى، راديولوزى و آزمايشًاه

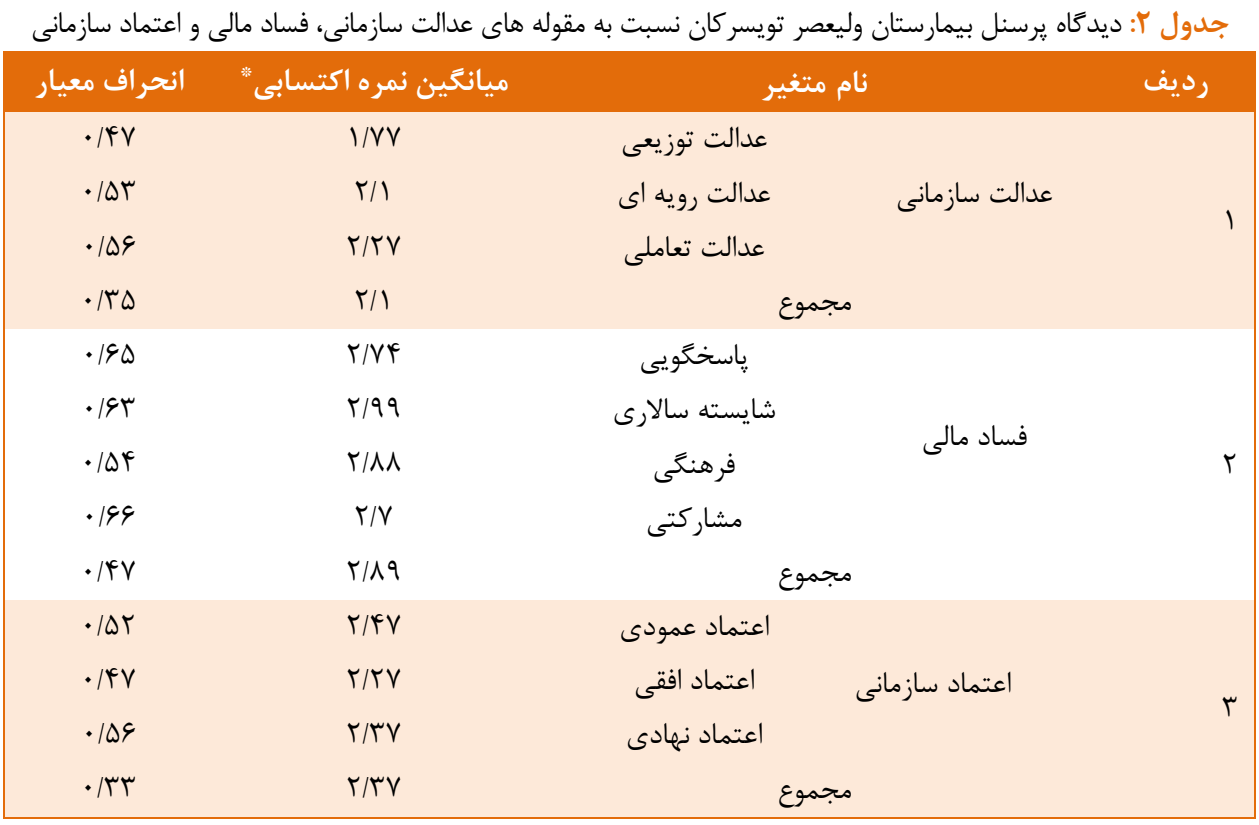

I I/RF * 
جدول "ّ: ضريب همبستخى بين مقوله هاى عدالت سازمانى، فساد مالى و اعتماد سازمانى

\begin{tabular}{|c|c|c|c|}
\hline اعتماد سازمانى & فساد مالى & عدالت سازمانى & \\
\hline - & - & 1 & عدالت سازمانى \\
\hline- & - & - & P.Value \\
\hline - & 1 & . MTF & فساد مالى \\
\hline - & - & $.1 .1 \mathrm{~F}$ & P.Value \\
\hline 1 & $\cdot 111$ & - KV & اعتماد سازمانى \\
\hline - & $\cdot / T V$ & $<\cdot \mid \cdot \cdot 1$ & P.Value \\
\hline
\end{tabular}

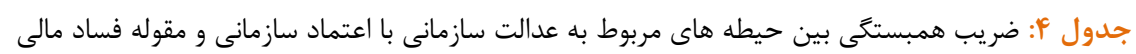

\begin{tabular}{|c|c|c|c|c|c|c|c|}
\hline \multirow[b]{2}{*}{ مشار كتى } & \multicolumn{2}{|c|}{ فساد مالى } & \multicolumn{5}{|c|}{ اعتماد سازمانى } \\
\hline & فر هنكى & شايسته سالارى & ضاسخََويى & نهادى & افقى & عمودى & \\
\hline .111 & .110 & .111 & $\cdot / 1 \mathrm{~F}$ & $\cdot / r$ & r &.$/ 11$ & عدالت توزيعى \\
\hline.$/ 1 T$ & ת & .1 .9 & .119 & זr/. & $\cdot / \cdot .1$ &.$/ \cdot 1 \mathrm{~V}$ & P.Value \\
\hline$\cdot 1 \cdot 1$ & .1 .9 & .1 .9 & $\cdot 1 \cdot 1$ & . At & $\cdot / \pi \Delta$ & $\cdot|4|$ & عدالت رويه اى \\
\hline (T\& & $\cdot / \mu \Lambda$ & $\cdot / 4 \Delta$ & $\cdot|f|$ & $<\cdot / \cdot \cdot \mid$ & $<\cdot / \cdot \cdot 1$ & $\cdot 1 \cdot \cdot 1$ & P.Value \\
\hline • & . & 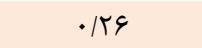 & $\cdot|\pi|$ & dete & $\cdot / F T$ & $\cdot|f|$ & عدالت تعاملى \\
\hline$<\cdot|\cdot \cdot|$ & $<\cdot|\cdot \cdot|$ & $<\cdot / \cdot \cdot 1$ & $<\cdot / \cdot \bullet \mid$ & $<\cdot|\cdot \cdot|$ & $<\cdot|\cdot \cdot|$ & $<\cdot|\cdot|$ & P.Value \\
\hline
\end{tabular}

سازمان و بهبود سيستم جبران حقوق و مزايا اقدام نمايند.

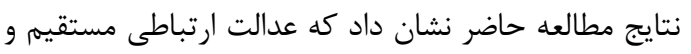

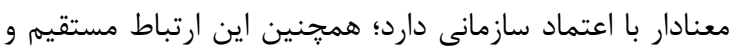

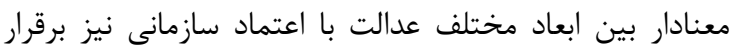

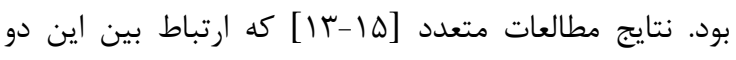

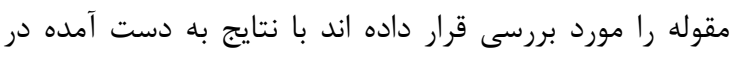

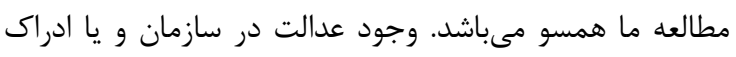

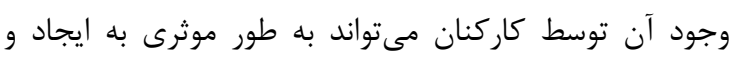

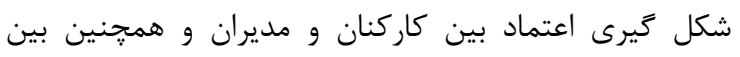

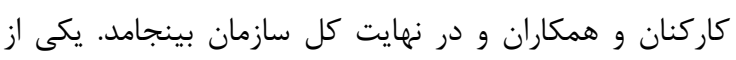

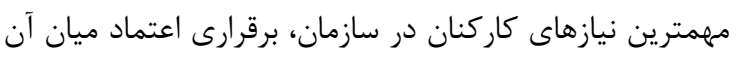

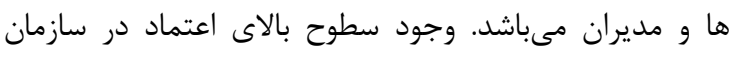

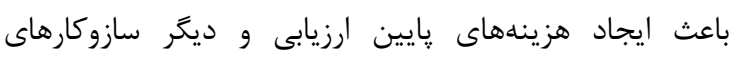

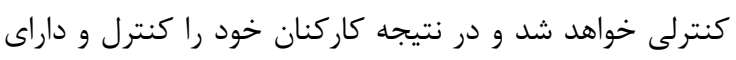

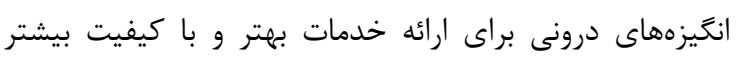

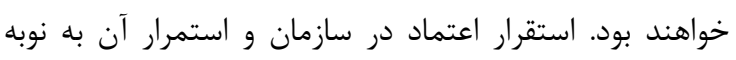
خود سبب اعتماد بيشتر و روحيه بالاى كاركنان و به تبع آن آن

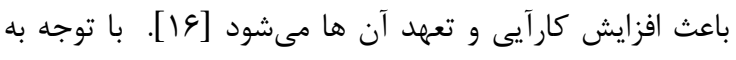

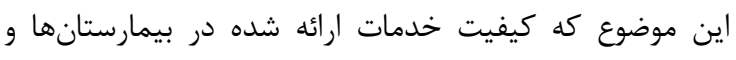
مراكز ارائه دهنده خدمات درمانه ديفيت از ازدمات الهميت بالايى برخوردار

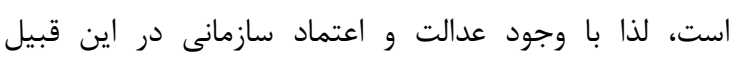
سازمانها اين مهمم دست يافتنى خواهد بود.

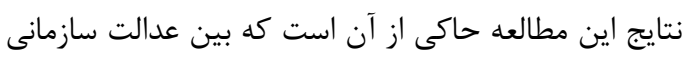

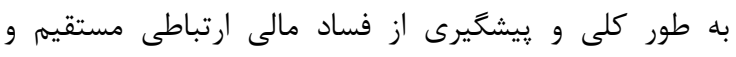

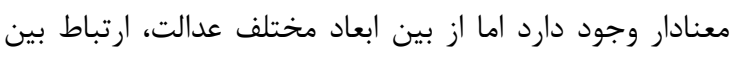

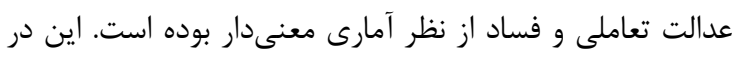

عدالت سازمانى با ساير ابعاد فساد مالى ارتباط معنادار

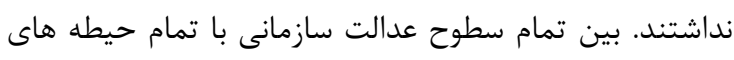

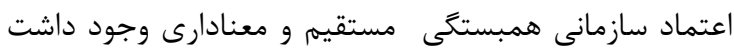

. $(\mathrm{P}<\cdot / \cdot \Delta)$

بحث

مطالعه حاضر با هدف تعيين ارتباط عدالت سازمانى، اعتماد

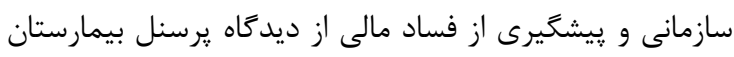

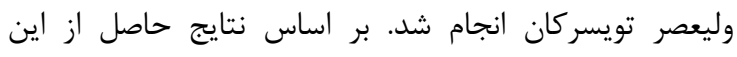

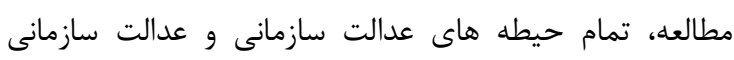

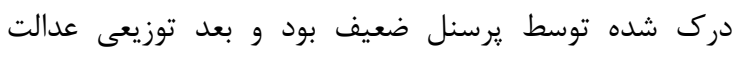
سازمانى نسبت به ساير ابعاد نمره كمترى را به خود اختصاص

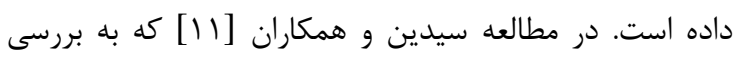

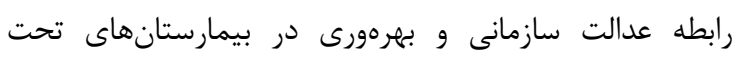

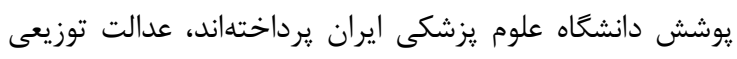

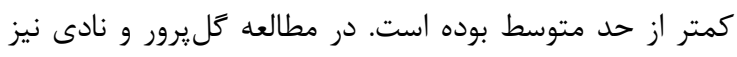

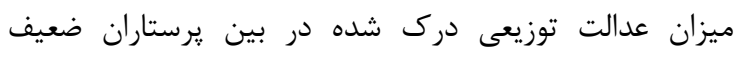

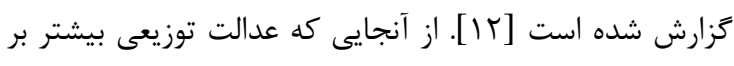

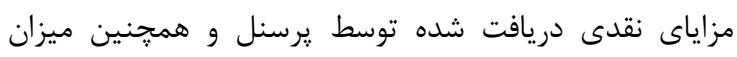
وظايف و مسئوليتهاى محول شده به كاركنان تاكيد دارد،

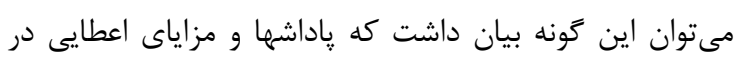

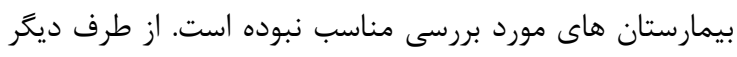

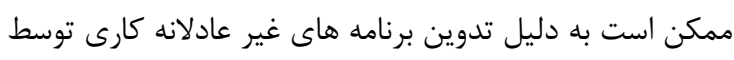

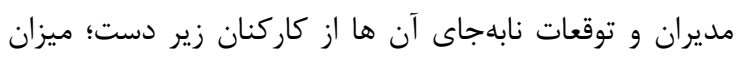

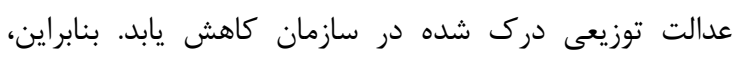

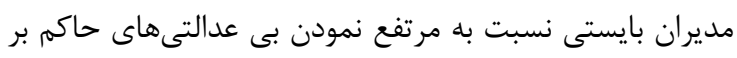


در مطالعه حاضر محدوديتهايى وجود داشت؛ از جمله اين

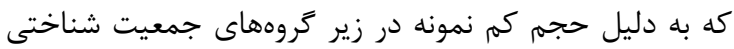

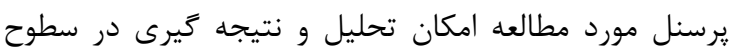

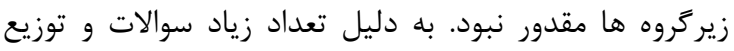

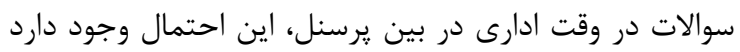

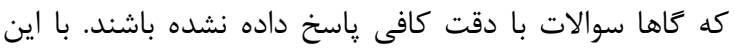

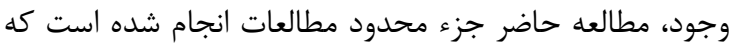

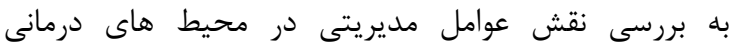

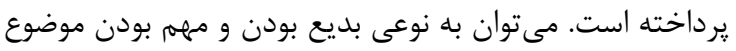

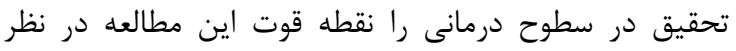

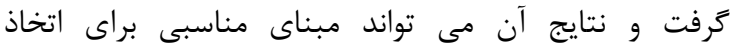

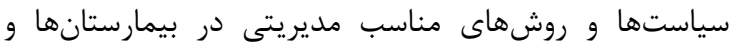

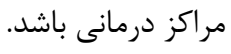

نتيجه كيرى با توجه به نتايج مطالعه حاضر ارتقاى عدالت سازمانى مى لـى

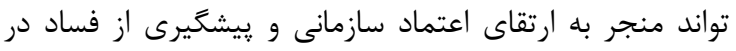

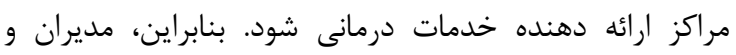

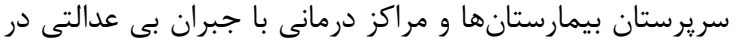

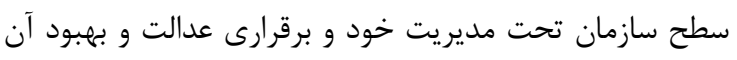

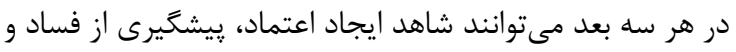
به تبع آن افزايش بهره ورى و بازدهى كاركنان باشند.

$$
\text { تشكر و قلرو النى }
$$

اين زيزوهش بركرفته از پايان نامه در مقطع كارشناسى مآى

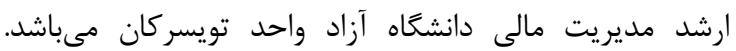
نويسندكان بر خود لازم مى مانند از زحمات يرسنل محترم

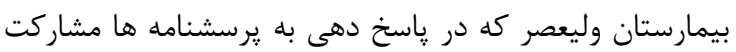

$$
\text { داشتند، قدردانى به عمل آورند. }
$$

تضاد منافع اين مطالعه براى نويسندكان هيج كَّنه تضاد منافعى

$$
\text { نداشته است. }
$$

\section{REFERENCES}

1. Kaufmann D, Kraay A, Mastruzzi M. Governance matters VI: governance indicators for 1996-2006. World Bank Policy Research Working Paper. 2007(4280):1-94.

2. Kaufmann D, Kraay A. Growth without governance. Economia. 2002;3(1):169-229.

3. Mehdad A, Dehghan E, Golparvar M, Shoja A. The relationship between psychologically healthy work place' components and organizational commitment and organizational trust among employees of Sar-Khoon and Qushm gas refinery incorporation. Knowledge \& Research in Applied psychology. 2012;13(2):71-80. (Persian)

4. Danaeifar H, Rajab-zadeh A, Hasiri A. Improving Internal Organizational Trust in the Public Sector: Investigating the Role of Managerial Competency. Management research. 2009;2(4):59-90. (Persian)
حالى است كه در مطالعه تقىزاده و سلطانى [IV] كه در شركتهاى توليد كننده خودرو انجام شده است، ابعاد توزيعى و

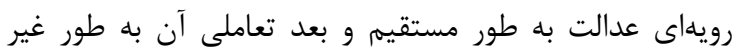

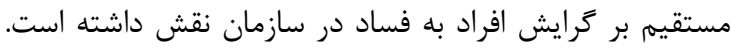

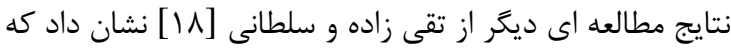

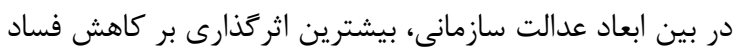

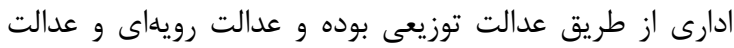

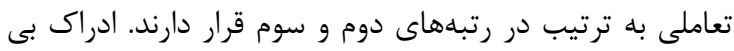

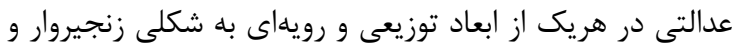

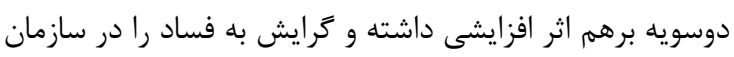

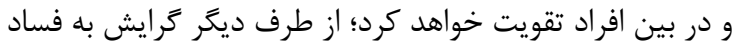

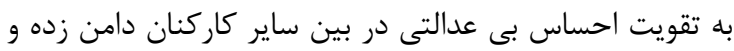
همجنين درست نبودن رويههاى سازمانى را در بـى بـى خواهد

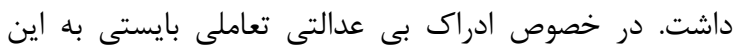

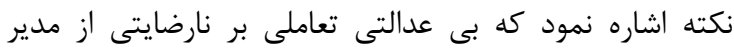

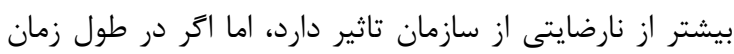

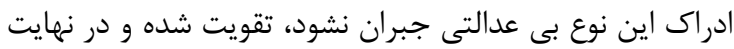

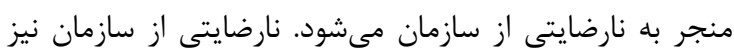

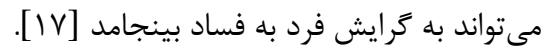

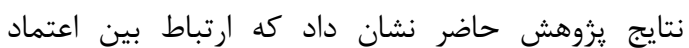
سازمانى و بيشخيرى از فساد از نظر آمارى معنى دار نمى باشئ.

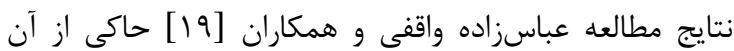
است كه عوامل فردى در بروز فساد نسبت به عوامل سازمانى و ودئ محيطى از تاثير بيشترى برخوردار مىباشد. در راستاى تبيين

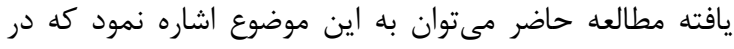

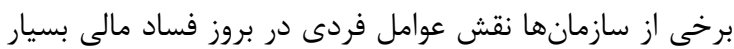

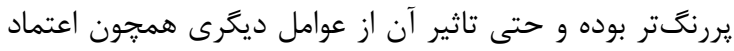

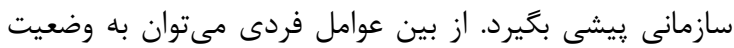

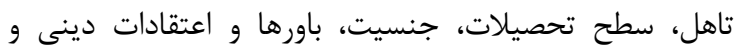

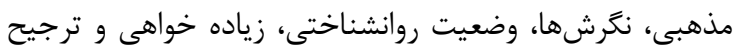

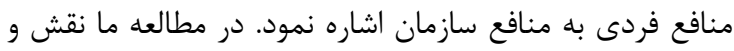

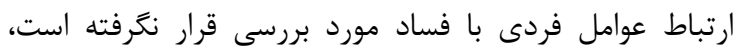

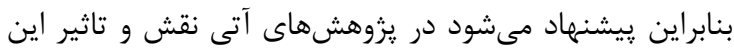
دسته عوامل نيز مورد بررسى و مطالعه قرار بخيرد.

5. Salimi G, Pourezzat AA. The Effect of Perceived unfairness in the organization on Tendency of corruption. Strategic Management Thought. 2010;4(1):131-59. (Persian)

6. Hubbell AP, Chory Assad RM. Motivating factors: Perceptions of justice and their relationship with managerial and organizational trust. Communication studies. 2005; 56(1):47-70.

7. Haghighatian M, Karimizadeh S, Nazari J. A Study of Some Factors Affecting Administrative Corruption Among Administrative Organizations in Yazd. Journal of Applied Sociology. 2012;23(48):125-42. (Persian)

8. DeConinck JB. The effect of organizational justice, perceived organizational support, and perceived supervisor support on marketing employees' level of trust. Journal of Business Research. 2010;63(12):1349-55. 
9. Nazem F, Lajevardi A. A structural model for organizational justice in oil industry based on managers' emotional intelligence and knowledge management. Journal of Teaching and Marine Sciences. 2018;4(4):78-91. (Persian)

10. Nadi M, Moshfeghi N, Siadat SA. A Structural Equation modeling Study of the Relationship between the Dimensions of Organizational Justice, Trust, Continuous and Affective Commitment with Teacher's Perceived Self-efficacy. New Approach In Educational Administration. 2014; 4(16): 1942. (Persian)

11. Seyedin SH, Ahadinejad B, Tourani S, Rajabifard F. The Relationship between Employees` Perception of Organizational Justice and Their Productivity in Selected Educational Hospitals at Iran University of Medical Sciences. Bioethics Journal. 2014; 4(13): 97-116. (Persian)

12. Golparvar M, Nadi MA. Perceptions of Justice with Customer - Oriented Behaviors among Nurses. Journal of Health Administration. 2009;12(35): 61-70. (Persian)

13. Carr JD, Maxwell SR. Police officers' perceptions of organizational justice and their trust in the public. Police Practice and Research. 2017;11:1-5.

14. Van Craen M. Fair policing from the inside out. In The politics of policing: Between force and legitimacy 2016 Jun 10 (pp. 3-19). Emerald Group Publishing Limited.

15. Van Craen M, Skogan WG. Achieving fairness in policing: The link between internal and external procedural justice. Police quarterly. 2017;20(1):3-23.

16. Jazani N, Soltani SH. The Impact of Organizational Justice on Organizational Commitment in the Mediating Role of Organizational Trust. Journal of Development Management and Evolution. 2016; 25: 27-36. (Persian)

17. Taghizadeh H, Soltani-Fesaghandis GH. Investigating the Role of Organizational Justice on Employee's Corruption Tendency in the Organization. Organizational Culture Management. 2017; 15(3): 529-550. (Persian)

18. Taghizadeh H, Soltani-Fesghandis GH. Prioritization of organizational justice dimensions from the viewpoint of Institutional Corruption decrease Using Cook and Seiford Approach. The Journal of Sociology Studies. 2018; 10(37): 43-55. (Persian)

19. Abbaszadeh-vaghefi $\mathrm{SH}$, Delkhah J, Forouzande L. Identification of Native Causes of Corruption: Case Study of Tehran Municipality. Journal of Audit Science. 2017; 17(68). (Persian) 